C. V. Jones, from the University Department of Electrical Power Engineering. Ample opportunity for discussion was available at the end of each lecture, and Dr. Gibbs encouraged and guided informal discussions each evening. The enthusiastic and often heated arguments which took place may be considered as a measure of the success of the course.

Since some of the students had no previous knowledge of tensor analysis, the opening lectures were devoted to the elements of matrix algebra and its application to electrical problems. The discussions showed that those to whom the subject was new were impressed by the practical nature of the methcd in its applications to numerical analysis. It was shown that the equation $V=Z I$ could be applied directly to complex circuits by replacing the quantities $V, I$ and $Z$ by the corresponding matrices. The use of compound matrices in obtaining the inverse of $Z$ was explained and the delta-star transformation and Thevenin's theorem were included as special cases of matrix transformation.

The introduction of tensor analysis followed the general lines developed by Crabriel Kron, who in 1934 made the first of his significant contributions to the mathematical treatment of electrical machines and networks by tensor methods. It was shown that the simple transformation of co-ordinates in geometry or field analysis, $A^{\alpha}=C_{a}^{\alpha} A^{a}$, could be used in electrical systems for interconnecting the windings of machines and networks. The fact that power is invariant to such an interconnexion leads to the following equa-

tions : $I^{\alpha}=C_{a}^{a} I^{\alpha a} ; V_{\beta}=C_{\beta !}^{b !} V_{b}^{z} ; Z_{\gamma \delta}=Z_{c a} C_{\gamma}^{\dot{s}} C_{\delta}^{d}$;

where the Greek affixes indicate quantities in the new system. Since static networks form a holonomic electrical system, they can bo analysed by tensor transformations. However, when windings are rotating with respect to each other they may have non-holonomic constraints, depending on the reference axes chosen. Some useful reference axes (such as those rotating with a synchronous flux wave) can be included only by use of non-holonomic equations. The general analysis of machines involves these more advanced concepts, which were next introduced. In particular, intrinsic and covariant derivatives of vectors and tensors are required. Stress was laid upon the work of Ricci, which showed that if in a differential equation which holds for rectangular Cartesian co-ordinates, ordinary derivatives be replaced by intrinsic derivatives and partials by covariant derivatives, then the modified equations hold for general curvilinear co-ordinates. The application of this theorem to electrical machinery is as follows. If the tensor equation of a stationary machine is

$$
V_{\alpha}=R_{\alpha \beta} i^{\beta}+L_{\alpha \beta} \frac{\mathrm{d} i^{\beta}}{\mathrm{d} t}
$$

then when the machine is rotating the corresponding equation is

$$
V_{\alpha}=R_{\alpha \beta} i^{\beta}+L_{\mu \beta} \frac{\delta i^{\beta}}{\delta t}
$$

where $\frac{\delta i \beta}{\delta t}$ is the intrinsic derivative and

$$
\frac{\delta i^{\beta}}{\delta t}=\frac{\mathrm{d} i \beta}{\mathrm{d} t}+\Gamma_{\gamma \alpha}^{\beta} i^{\gamma} i^{\prime t}
$$

The general machine equation then becomes

$$
V_{\alpha}=R_{\alpha \beta} i^{\beta}+L_{o \beta} \frac{\mathrm{d} i^{\beta}}{\mathrm{d} t}+\Gamma_{\beta \gamma, \alpha} i^{\beta} i \gamma
$$

The different forms of $\Gamma_{\beta \gamma, a}$ which arise under different operating conditions and with different reference axes were next introduced. The terms arising because of non-holonomic constraints were studied in detail.

The long-established rules and concepts of the tensor calculus were seen to lead to a generalized theory of electrical machinery. The power and flexibility of these tensor applications, due to Kron, are becoming more widely recognized.

\section{ROYAL BOTANIC GARDENS, KEW REPORT FOR 1956}

7 HE review of the work of the Royal Botanic Gardens, Kew, during 1956 follows the general pattern of earlier reports (Kew Bull., No. 1 ; 1957). During the year Sir Edward Salisbury, who had been the director for thirteen years, retired and was succeeded by Dr. George Taylor, keeper of botany in the British Museum (Natural History).

The Herbarium staff, as usual, has dealt with a truly vast amount of material and has been visited by some 4,455 botanists, many of these from the Commonwealth and other countries overseas. The report also records extensive and varied inquiries on botanical matters and the receipt of many consignments of plants. The work on several floras has been sustained and constitutes a notable effort in scholarship.

In the Department of Economic Botany the number of inquiring visitors has been greater than in the previous year. Inquiries cover a great deal of ground, often of an interesting and important character. It would be impossible in a short note to do more than touch on one or two points. The distribution of economic plants still ranks as an important function of this section. The propagation of cacao was actively continued during the greater part of the year, and many plants were dispatched from the Quarantine House. These consisted chiefly of materials collected in Colombia during 1952 and forwarded to $\mathrm{Kew}$ in 1954 via the Imperial College of Tropical Agriculture in Trinidad. After the required period of supervision in quarantine, the plants were propagated as rooted cuttings, which were sent on to the West Africa Cacao Research Institute as materials for its breeding programme. It is noted that a variety of cacao from a widely different source, known as Lafi No. 7 from Samoa, has now been propagated and distributed. This material has aroused wide interest because of its reputation for high yielding capacity and its possible disease-resistance properties. Rooted cuttings have now been sent to Trinidad, West Africa and Malaya for trials under differing conditions. The work of the Quarantine House in relation to banana problems follows the lines reported on in previous years. Special interest is attached to some varieties of the diploid $M u s a$ acuminata, collected in New Guinea and Malaya, which in due course will be used in the breeding programme in the Caribbean.

An important result of the work of the Jodrell Laboratory is that a draft of practically the whole of 
a work on the anatomy of the grasses has been prepared and should, it is hoped, be ready for the press before the end of 1957 ; and anatomical studies of other monocotyledons have been published or are in progress. The routine work of the Laboratory is concerned with the very diverse, and sometimes diverting, materials submitted for examination: in 1956 a piece of wood from Herod's palace at Jerusalem was found to be Juniperus oxycedrus.

The report also deals comprehensively with the work in progress in the Gardens, including its several sections from the Arboretum to the Tropical House. It concludes with a record of the papers published during the year together with a staff list.

\section{W. WardLaW}

\section{THE CIVIL SERVICE \\ REPORT FOR 1956-57}

$\mathrm{T}$ HE ninety-first report of H.M. Civil Service Commissioners, covering the period April 1, 1956-March 31, 1957*, again notes a decrease in the number of candidates for the open competitions of the administrative class. Although the number of entries was the lowest since 1949 and only thirty. three out of the fifty vacancies allotted to this competition were filled, the entry for the 1957 competitions appears to be somewhat stronger both in number and in quality than that of 1956. To fill vacancies left by the 1955 open competition, a supplementary competition for the administrative class was held in the summer of 1956 to offer an opportunity to those who had remained at the universities for research, or had taken up other employment and had outstanding intellectual ability. of the twenty-one candidates, the five who were successful had been engaged in research or in university teaching since graduating. The limited competition for the administrative class was somewhat more successful than in the previous year, and the results of the innovations tried seem encouraging. Recruitment to the statistician class remained difficult and the number eompeting for the special departmental olass declined further. The open competitions for the executive class produced enough recruits to fill the vacancies notified, but it was only the adoption of a new competition based on the General Certificate of Education that maintained the level of recruitment among young people. 'The growing proportion of women candidates in some competitions, particularly those for the executive and clerical classes, suggests that the achievement of equal pay by 1961 is increasing the attractiveness for a woman of a career in the Civil Service. The method of continuous open competition was used for all scientific classes, and the results of the senior scientific officer/ scientific officer competitions were relatively satisfactory, especially in the senior grade, for which recruitment appears to be easier than that of scientific officers of the quality and in the numbers required by departments. The greatest deficiency was in filling posts for scientific assistants, though a fair number of the vacancies are being filled by temporary people who are gaining the two years experience required to qualify them for the competitions.

* Report of Her Majesty's Civil Service Commissioners for the period 1st April, 1956, to 31st March, 1957. Pp. 40. (London : H.M.

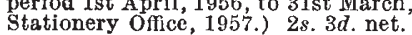

The quality of candidates attracted by the research fellowship competition remains high, and the departments concerned appear to have been impressed very favourably by the work of those in the past. Of the twenty-seven fellowships offered this year, nine senior and thirteen junior fellowships have been awarded. Although the competition for patent examiners took a slight turn for the better, the number of vacancies is so large, and the problem of recruitment so difficult, that for a limited period candidates are being considered who hold honours degrees in non-scientific subjects. It remains as difficult as ever to recruit candidates with technical qualifications for the factory inspectorate. The information work of the Commission increased both in volume and in complexity and an information officer was appointed to organize and develop it. The arrangement made in 1955 whereby younger members of the administrative class act as links between the Civil Service and their own colleges or universities appears to fulfil a real need, and the arrangement made in December 1956 for sixty undergraduates, representing most of the British universities, to spend a week visiting Government departments also appeared to be a success.

\section{ACCIDENTS IN CHILDHOOD}

A YEAR ago the European Regional Office of the World Health Organization asked a group of experts from many countries to consider how accidents in childhood could be prevented. In most countries in Europe infant and child mortality has been steadily decreasing in recent years, and in many places has reached significantly low figures. Deaths due to infections and nutritional disturbances have fallen to a level considered unattainable only a few years ago. Against this, the death-rate due to accidents remains high and for many types of accidents has increased. As disease becomes more effectively controlled, accidents are assuming a proportionately greater importance. In some countries they have become the chief cause of death in childhood and adolescence and account for 30-40 per cent of all deaths in the age-group 1-19 years. Among certain groups of children, greater numbers are killed by accidents than by all other causes combined. This unenviable prominence of accidents in child mortality throughout Europe is due to the new and dangerous hazards introduced into many homes and countries by modern technological progress. The spread of electrification, especially in rural areas, the introduction of highly potent insecticides, the increasing numbers of motor-cars and bicycles on roads designed for thirteenth- to fifteenth-century traffic, may be cited as examples.

It is not only as a cause of death that accidents in childhood are important. The number of non-fatal accidents is very much larger $-100-200$ times greater and by some estimates even more.

In a preliminary survey the advisory group examined the main causes of accidents and at what ages they occurred*. These showed that mortality from accidents is highest at the pre-school age, lowest among school children, and again somewhat higher in adolescence. Since the beginning of this century,

* World Health Organization. Technical Report Series, No. 118 : Accidents in Childhood: Facts as a Basis for Prevention. Report of an Advisory Group. Pp. 40. (Geneva : World Health Organization ;
London: H.M. Stationery Office, 1957.) 1 Swiss franc; 1s. 9d.: 0.30 doliars. 